\title{
EFEITOS DA OCUPAÇÃO URBANA SOBRE A MACROFAUNA DE INVERTEBRADOS AQUÁTICOS DE UM IGARAPÉ DA CIDADE DE MANAUS/AM - AMAZÔNIA CENTRAL
}

\author{
Sérgio Ernani Nogueira CLETO FILHO', Ilse WALKER ${ }^{2}$
}

RESUMO - A qualidade da água e a fauna composta pelos macroinvertebrados aquáticos do Igarapé do Mindú, o qual tem suas nascentes em áreas florestadas e atravessa a cidade de Manaus (Amazonas, Brasil), foram estudadas de 1993 a 1995. Desmatamentos e ocupação das áreas ao longo do igarapé, juntamente com a poluição orgânica doméstica causaram drásticas alterações nas características físico-quimicas das águas e na composição da fauna aquática. Assim, temperatura da água, condutividade elétrica, $\mathrm{pH}$ e sedimentos em suspensão aumentaram significativamente, enquanto que os valores de oxigênio dissolvido na água diminuiram. Esses fatores de alterações, associados com a redução natural da velocidade de corrente d'água e aumento da radiação solar, resultaram em eutrofização e mudança marcante da fauna bentônica.

Palavras-chave: Amazônia, biodiversidade, eutrofização, macroinvertebrados aquáticos, urbanização.

\section{Effects of Urban Occupation on the Aquatic Macroinvertebrate from a Small Stream of} Manaus, Amazonas State, Brazil.

\begin{abstract}
Conditions of water quality and of the invertebrate fauna in the stream Mindú, originating in undisturbed forest area and crossing the city of Manaus/AM, were studied from 1993 to 1995 . Deforestation and invasive colonization along the headwater streams and pollution in the city center caused drastic alterations of the limnological and faunistic conditions. Thus, water temperature, conductivity, ph values and quantity of sediments in suspension rose significantly, while oxygen levels dropped. Together with the natural reduction of flow speed and increased solar radiation these alterations resulted in eutrophication and a marked change of the composition of the invertebrate fauna.
\end{abstract}

Key-words: Amazonia, aquatic macroinvertebrates, biodiversity, eutrophization, urbanization.

\section{INTRODUÇÃO}

Em várias regiões do mundo o acelerado e desenfreado crescimento urbano e populacional tem alterado e impactado drasticamente os ambientes terrestres e aquáticos como conseqüência das atividades humanas (Payne, 1986). No Brasil, os desmatamentos, ocupação e uso inadequado do solo, industrialização e poluição (aérea, terrestre e hídrica) nos centros urbanos, são exemplos de ações que tem diminuido a qualidade de vida da população além de causar drástica redução da biodiversidade tanto terrestre como aquática (Tundisi et al., 1995; Silva et al., 1998).

Em Manaus (Amazonas), cidade com cerca de 1,2 milhão de habitantes (IBGE, 1996), o processo de crescimento urbano e populacional tem apresentado padrão semelhante de comportamento porém mais acentuado nos últimos 30 anos com a implantação do Complexo Industrial. Os desmatamentos de áreas florestadas para posterior ocupação

1 INPA/CPEC/PPG; Caixa Postal 478 - Manaus/AM. (sergiocleto@bol.com.br).

2 INPA/CPEC (iwalker@inpa.gov.br). 
humana tem sido interpretados como os primeiros passos para a modificação e degradação ambiental com repercussão negativa para os corpos d'água e biota associada (Fonseca et al., 1982; Silva, 1995; Cleto Filho, 1998; Nava, 1999). Para os macroinvertebrados aquáticos diversos estudos foram realizados em paises de clima tropical e temperado mostrando como esses organismos se comportam diante das alterações na qualidade da água dos cursos d'água sendo, portanto, bioindicadores da qualidade da água (Lenat, 1984; Duncan et al., 1989; Callisto \& Esteves, 1996; Junqueira \& Campos, 1998). No entanto, na Amazônia brasileira poucas informações existem sobre os efeitos da urbanização e sua repercussão para os cursos d'água e biota associada. Visto que a população está crescendo e que as cidades na Amazônia são essencialmente associadas aos rios e igarapés como meio de transporte, fonte de alimento e lazer, estudos sobre os efeitos dos desmatamentos e urbanização são particularmente importantes e necessários. Um manejo adequado dos cursos d'águas urbanizados não somente evita doenças como também custos financeiros futuros para corrigir os erros do passado como demonstrado pelos problemas das cidades européias e do continente americano no último século.

Neste estudo as faunas aquáticas compostas pelos macroinvertebrados das águas naturais situadas em áreas florestadas e não impactadas e em áreas urbanizadas são comparadas e grupos específicos são identificados em relação com as qualidades fisicas e químicas das águas.

\section{ÁREA DE ESTUDO}

\section{Os igarapés ("riachos")} estudados - Mindú e Barro Branco pertencem à bacia hidrográfica do rio Negro, do qual são afluentes da margem esquerda. Estão situados no municipio de Manaus/AM ( $3^{\circ} 08^{\prime} \mathrm{Sul}$; $60^{\circ} 01^{\prime}$ Oeste) e drenam áreas de sedimentos fluviais terciários da Amazônia Central, Formação Alterdo- Chão, caracterizadas por solos arenosos e argilosos e pobres em nutrientes (Chauvel et al., 1987). As características físicas e químicas de suas águas e hidrologia dos trechos estudados são dados nas Tabelas 1 e 2.

O igarapé do Mindú é um dos principais igarapés urbanos que atravessam a cidade de Manaus/AM (Fig. 1). Seu percurso, das nascentes até o rio Negro, tem de 20 a $25 \mathrm{~km}$ de extensão (GPS; linha reta). Nesse estudo dividiu-se o igarapé do Mindú em: nascentes ou curso superior (igarapés 1 e 2 amostrados), curso intermediário atravessando o Parque Municipal do Mindú e o curso inferior na zona central da cidade. Este igarapé vem sofrendo, nos últimos 25 anos, intensos processos de degradação em função do acelerado crescimento urbano e populacional.

Suas nascentes, ainda em estado de preservação, estão localizadas em área de floresta primária distanciada 2 $\mathrm{km}$ dos núcleos de ocupação humana 
Tabela 1. Valores médios (x), mínimos e máximos e número de observações (n) de largura, profundidade, velocidade da água, sedimentos em suspensão e cor da água dos igarapés 1 e 2 (nascentes do Mindú), trecho no Parque Mindú, Zona central e Igarapé Barro Branco durante o periodo de 1993 a 1995.

\begin{tabular}{|c|c|c|c|c|c|}
\hline Loca is & Largura & $\begin{array}{l}\text { Profundid ade } \\
\text { (m) }\end{array}$ & $\begin{array}{l}\text { Velocidade da } \\
\text { água superficial } \\
(\mathrm{m} / \mathrm{min})\end{array}$ & $\begin{array}{l}\text { Sedimentos } \\
\text { em Suspensăo } \\
(\mathrm{mg} / \mathrm{l})\end{array}$ & Cor da água \\
\hline Igarapé 1 & $\begin{array}{c}x=0,75 \\
0,40-1,5 \\
n=19\end{array}$ & $\begin{array}{c}x=0,15 \\
0,02-0,5 \\
n=15\end{array}$ & $\begin{array}{c}x=10,2 \\
5,4=20,4 \\
n=7\end{array}$ & $\begin{array}{c}x=3,8 \\
2,5=4,5 \\
n=5\end{array}$ & Clara \\
\hline Igarapé 2 & $\begin{array}{c}x=0,74 \\
0,45-1,1 \\
n=10\end{array}$ & $\begin{array}{c}x=0,12 \\
0,03-0,35 \\
n=10\end{array}$ & $\begin{array}{c}x=13,8 \\
7,2-18 \\
n=7\end{array}$ & $\begin{array}{c}x=3,7 \\
3,1=4,6 \\
n=5\end{array}$ & Clara \\
\hline $\begin{array}{l}\text { Igarapé Ba rro } \\
\text { Branco }\end{array}$ & $\begin{array}{c}x=0,9 \\
0,2-2,1 \\
n=12\end{array}$ & $\begin{array}{c}x=0,45 \\
0,03-0,9 \\
n=14\end{array}$ & $\begin{array}{c}x=25,8 \text { (SECA) } \\
16,2-42 \\
n=11\end{array}$ & $\begin{array}{c}0,37-0,8 \\
n=4\end{array}$ & $\mathrm{Clara}$ \\
\hline $\begin{array}{l}\text { Parque Mindú } \\
\text { (PMM) }\end{array}$ & $\begin{array}{l}x=7,0 \\
3=13 \\
n=10\end{array}$ & $\begin{array}{c}0,6=1,8 \\
n=6\end{array}$ & $\begin{array}{c}x=25,8 \text { SECA) } \\
14,4-46,8 \\
n=7 \\
x=5,4 \text { (CHEIA) } \\
4,2=7,8 \\
n=7\end{array}$ & $\begin{array}{c}x=120,8 \\
75=237 \\
n=7\end{array}$ & Branca \\
\hline $\begin{array}{l}\text { Zona central da } \\
\text { cidade de Manaus }\end{array}$ & $\begin{array}{c}x=14,95^{\text {SECA) }} \\
4,5 \cdot 32 \\
n=30 \\
\text { até } 500 \mathrm{~m}^{\text {(CHEIA) }}\end{array}$ & $\begin{array}{c}x=0,76^{(S E C A)} \\
0,4-1,5 \\
n=8 \\
\text { até } 8-11^{\prime 1 !}\end{array}$ & $\begin{array}{c}x=21,6 \text { (SECA) } \\
13,8-42,6 \\
n=7 \\
x=4,5 \text { (CHEIA) } \\
3-6 \\
n=5\end{array}$ & $\begin{array}{c}x=195 \\
123=285 \\
n=7\end{array}$ & Branca \\
\hline
\end{tabular}

Observaçăo: Os valores de largura e profundidade foram tomados durante períodos de seca.

(') Cota de elevaçăo do Rio Negro (PORTOBRÁS: anos de 1993, 1994 e 1995).

(2) Segundo a classificação de SIOLI, H. (1975)

na periferia da cidade; bairro Jorge Teixeira/Tancredo Neves. Nesta área os igarapés são meandrosos, pouco profundos (média $<0,5 \mathrm{~m}$ ), estreitos (média $<1 \mathrm{~m}$ ) com os leitos arenosos e substratos aquáticos diversificados tal como liteira (folhiço) e raizes submersas, troncos e galhos de diversos tamanhos e diâmetros e ausência de plantas aquáticas. As águas são claras enquanto que nos cursos intermediário e inferior, que correspondem aos trechos urbanizados, tornam-se barrentas.

O Parque Mindú - curso intermediário - compreende uma área de 31 hectares e composição florística formada, na sua maioria, por representantes de floresta secundária (jatobá; Hymenea sp.
(Caesalpinaceae); murici; Byrsonima sp. (Malpighiaceae); tucumã; Astrocaryum sp. (Arecaceae); cardeiro; Scleronema sp. (Bombacaceae); cupiuba; Goupia sp. (Celastraceae); carapanaúba; Aspidosperma sp. (Apocynaceae); lacre; Vismia sp. (Clustaceae); embaúba; Cecropia sp. (Moraceae); marupá; Simarouba sp. (Simarubaceae). Nas margens do igarapé, que torna-se mais profundo $($ média $=1,1 \mathrm{~m})$ e menos meandroso, a vegetação é arbustiva predominando os capins enraizados canarana (Echinochloa sp.) e membeca (Paspalum sp.). O Parque está distanciado $15 \mathrm{~km}$ das nascentes e a $7 \mathrm{~km}$ da zona central da cidade.

O curso inferior do Mindú passa pelo centro da cidade desaguando no 


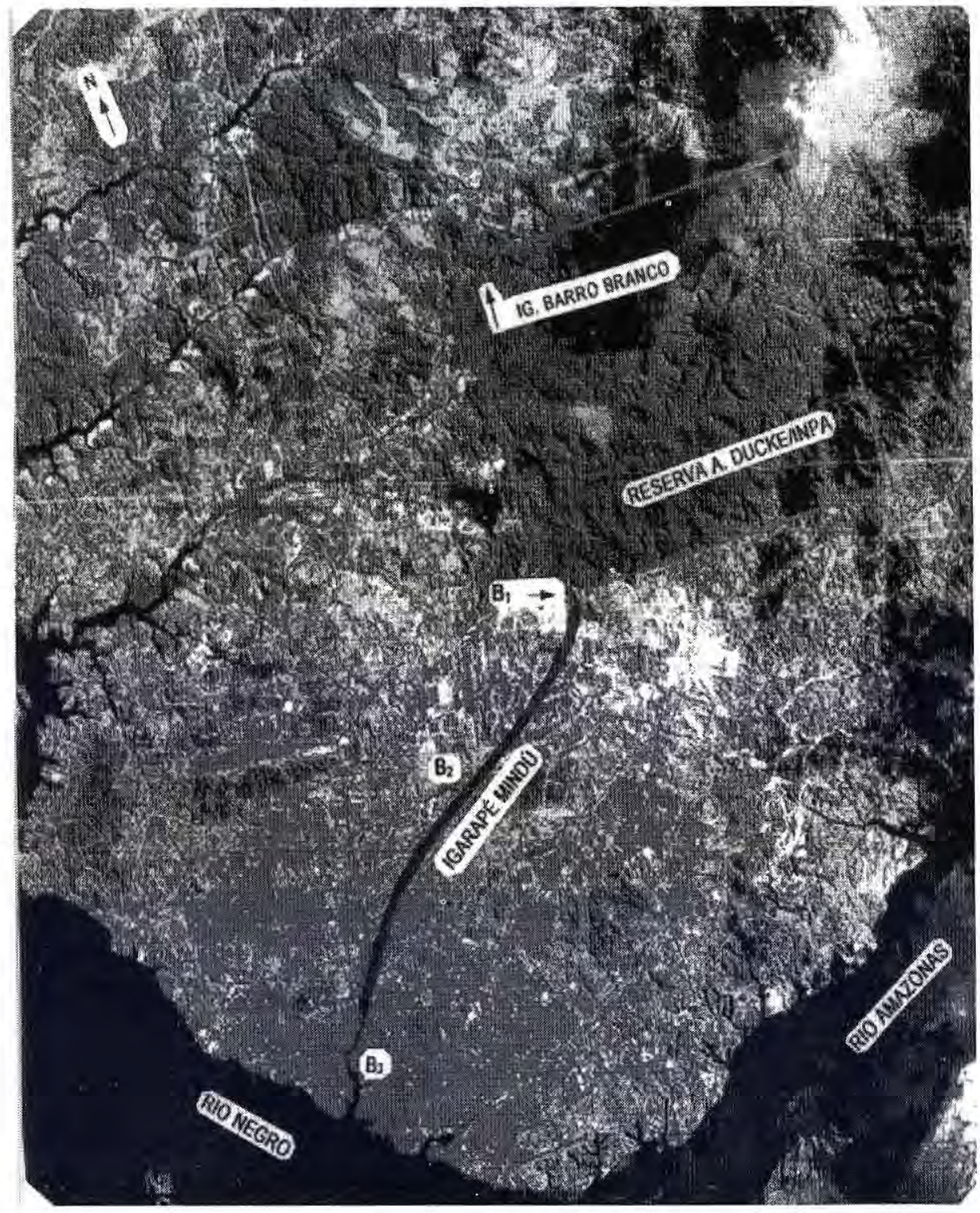

Figura 1. (março/1987): Imagem de satélite mostrando a cidade de Manaus/AM e os trechos dos igarapés estudados. $\mathrm{A}=$ Reserva Ducke (Igarapé Barro Branco); $\mathrm{B}=$ Igarapé do Mindú $(\mathrm{B} 1=$ igarapés 1 e 2; $\mathrm{B} 2=$ Parque do Mindú e $\mathrm{B} 3=$ Zona central da cidade $) . \mathrm{O}$ traçado feito corresponde ao percurso do Igarapé do Mindú pela cidade de Manaus. 
dissolvidos). Para medir a velocidade de corrente da água de superfície foram utilizados pedaços de isopor que eram colocados na superfície da água e medido, com um cronômetro, o tempo gasto para percorrer distâncias conhecidas; os valores obtidos foram calculados em metros/minuto.

\section{Delimitação dos trechos de amostragens:}

Trechos de $100 \mathrm{~m}$ foram delimitados nos igarapés 1, 2, Barro Branco e no Parque Mindú onde, a cada $10 \mathrm{~m}$ era retirada uma amostra da fauna nos substratos formados por liteira submersa e raizes submersas (igarapés 1, 2 e Barro Branco) e nos capins marginais enraizados (Parque Mindú). $\mathrm{Na}$ zona central foi delimitado um trecho de $500 \mathrm{~m}$ ao longo do qual 20 amostras foram retiradas.

\section{Coleta dos Macroinvertebrados} Aquáticos:

As coletas dos macroinvertebrados aquáticos foram feitas com o auxilio de um "rapiché" (rede de mão; área $=0,18 \mathrm{~m}^{2}$ ) e malha de $1 \mathrm{~mm}$. Após cada passada de rede, os organismos capturados eram retirados manualmente com o auxilio de uma pinça utilizando-se um esforço de procura padronizado em 15 minutos/ rede e posteriormente armazenados em frascos contendo álcool $96^{\circ} \mathrm{e}$ etiquetados. Desse modo, nas condições das amostragens o número de organismos capturados em 15 minutos/rede é aproximadamente proporcional à densidade dos organismos nos substratos. A identificação dos organismos se deu no nível de família.

\section{Avaliação Estatística dos Dados:}

Para os fatores físicos e químicos das águas entre os igarapés e seus trechos utilizou-se o teste $\mathrm{t}$ - Student ( $\mathrm{p}<0,05$; programa estatístico Systat versão 5.02 ; 1991). Para os dados biológicos utilizou-se do índice de diversidade de Shannon (H'; programa estatístico Statistical Ecology Ludwig \& Reynolds, 1988); similaridade (indice de Jaccard $=\% \mathrm{~S}$; Southwood, 1966) e teste Qui Quadrado ( $\mathrm{p}<0,05$; programa estatístico Statgraphics versão 5.0; 1991).

\section{RESULTADOS}

\section{Parâmetros Físicos e Químicos das águas.}

Os valores de temperatura, $\mathrm{pH}$, condutividade elétrica e sedimentos em suspensão dos trechos naturais não urbanizados (igarapés 1, 2 e Barro Branco) foram significativamente menores daqueles obtidos nos trechos urbanizados (Parque Mindú e zona central) que apresentaram, por sua vez, valores de oxigênio dissolvido consideravelmente menores daqueles encontrados nos trechos naturais (Tabs 1 e 2; Figs 2 a 5). Temperatura elevada não somente dificulta a dissolução do oxigênio na água como aumenta o consumo desse gás devido aos processos de respiração e de decomposição orgânica agravando, 
ainda mais, o déficit (Esteves,1988). No Parque Mindú e na Zona central, o volume de matéria orgânica (esgotos domésticos) que é despejado continuamente, a decomposição das plantas aquáticas, a intensa atividade microbiológica são fatores que contribuíram para o baixo teor do oxigênio e aumento nos valores de condutividade elétrica das águas.

Os valores dos sedimentos em suspensão nos trechos urbanizados apresentaram uma carga de sedimentos em fluxo entre 30 a 300 vezes maior que aqueles obtidos para os trechos naturais. Essa grande variação refletiu, em parte, variações sazonais visto que a quantidade de sedimentos em suspensão é uma função do fluxo de água que varia, por sua vez, com os níveis de precipitação e com as fases de inundações. Porém, na área urbana de Manaus, devido à crescente expansão urbana, aos intensos desmatamentos e à ocupação rápida e desordenada do solo, principalmente nas áreas periféricas da cidade, as águas deixam de ser claras, como originalmente, e passam a ser barrentas/"águas brancas" contendo elevadas quantidades de sedimentos argilosos em suspensão. Salienta-se que, independente dos processos de urbanização, as áreas das nascentes que estão localizadas numa altitude superior aos trechos do Parque Mindú e Zona central, são naturalmente áreas onde os processos erosivos são mais acentuados transportando sedimentos para áreas mais baixas consideradas zonas de sedimentação ou deposição; no caso o Parque Mindú e a Zona central. Evidentemente, os desmatamentos marginais aos cursos d'águas potencializam e aceleram o processo erosivo e de lixiviação do solo.

\section{A Comunidade Biológica: Macroinvertebrados Aquáticos:}

Das 60 famílias de invertebrados aquáticos capturados nos diferentes trechos dos igarapés estudados, 35 a

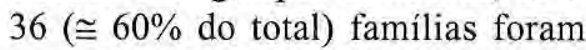
encontradas nos igarapés 1, 2 e Barro
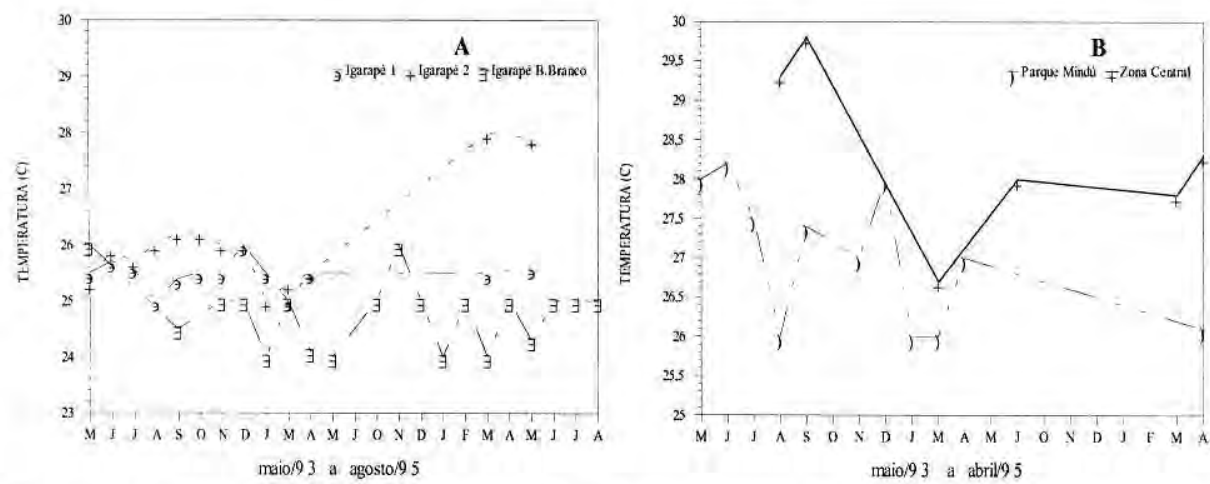

Figura 2. Variação temporal da temperatura $\left({ }^{\circ} \mathrm{C}\right)$ dos igarapés do Mindú (igarapé 1, igarapé 2 , Parque Mindú e Zona central) e Barro Branco durante o periodo de 1993 a 1995. 

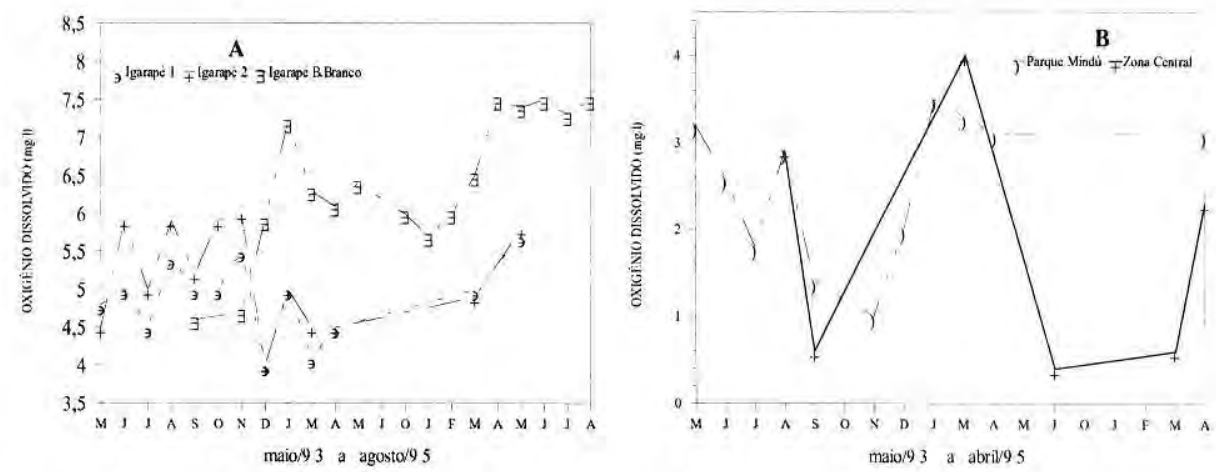

Figura 3. Variação temporal do oxigênio dissolvido $(\mathrm{mg} / \mathrm{l})$ dos igarapés do Mindú (igarapé 1, igarapé 2, Parque Mindú e Zona central) e Barro Branco durante o período de 1993 a 1995.
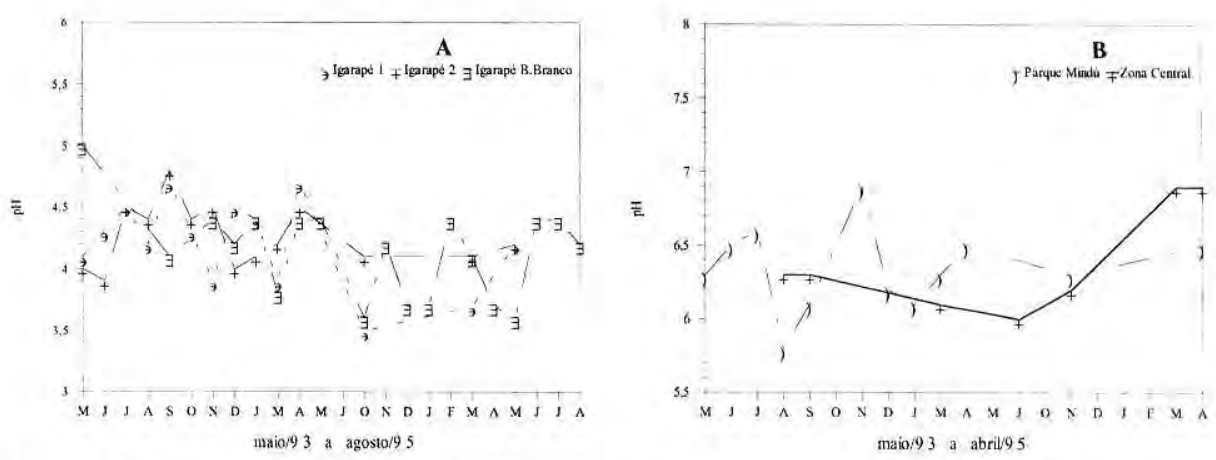

Figura 4. Variação temporal do $\mathrm{pH}$ dos igarapés do Mindú (igarapé 1, igarapé 2, Parque Mindú e Zona central) e Barro Branco durante o período de 1993 a 1995.
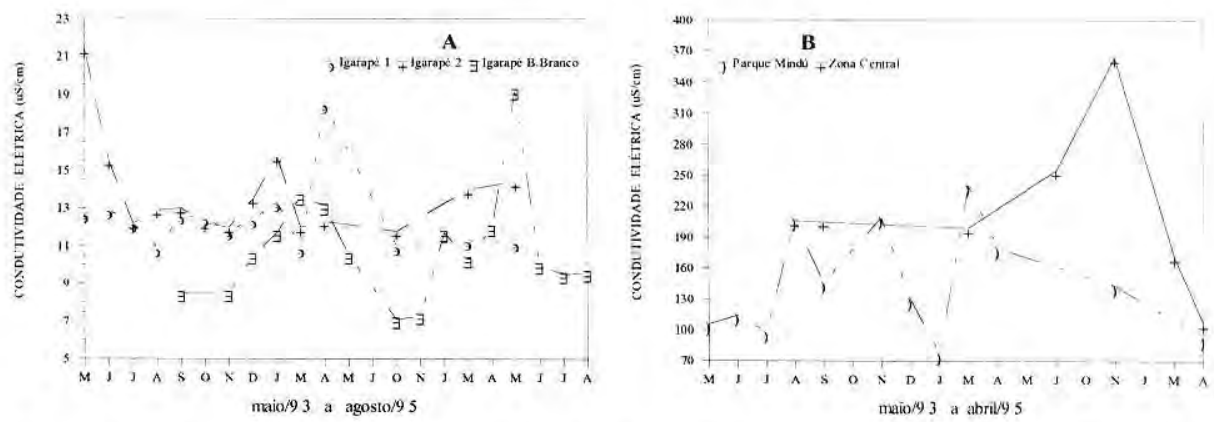

Figura 5. Variação temporal da condutividade elétrica $(\mu \mathrm{S} / \mathrm{cm})$ dos igarapés do Mindú (igarapé 1, igarapé 2, Parque Mindú e Zona central) e Barro Branco durante o período de 1993 a 1995. 
Branco e 26 e 29 famílias $(<50 \%$ do total) no Parque Mindú e Zona central, respectivamente (Tab. 3; Fig. 6). Isto indica que mesmo com o aumento em tamanho, volume e conteúdo de nutrientes nas águas que fluem pelos trechos urbanizados, a diversidade - no nível de família - diminuiu, demonstrando que as condições abióticas para a biodiversidade se deterioraram ao longo do igarapé que atravessa a cidade.

A macrofauna capturada nos igarapés 1,2 e Barro Branco confirmou o padrão de composição da macrofauna aquática encontrada nos ambientes florestados e não impactados da Amazônia Central (Fittkau, 1977; Walker \& Ferreira, 1985; Oliveira, 1992 e Walker, 1994). Os invertebrados mais representativos foram: Odontoceridae, Calamoceratidae e Helicopsychidae (Trichoptera), Leptophlebiidae (Ephemeroptera), Gomphidae e Libelullidae (Odonata), Chironomidae (Diptera), Perlidae (Plecoptera), Veliidae e Naucoridae (Hemiptera) e Hydrophilidae e Elmidae (Coleoptera). Também as três espécies de camarões da família Palaemonidae: Macrobrachium inpa, Macrobrachium nattereri e Pseudopalaemon amazonensis encontradas geralmente nos igarapés da terra firme (Kensley \& Walker, 1982), foram capturadas nas cabeceiras do igarapé Mindú e no igarapé Barro Branco.

Já nas áreas urbanizadas predominaram os Chironomidae (Diptera), Coenagrionidae (Odonata), Belostomatidae (Hemiptera), Ancylidae e Pilidae (Mollusca) e
Hirudinea enquanto Trichoptera, Plecoptera e Decapoda (camarões) não foram capturados. No Parque Mindú a ordem Decapoda foi representada pelos caranguejos (Trichodactylidae) que foram encontrados em número reduzido (4 individuos). Os Ephemeroptera tiveram uma participação modesta com o predomínio da familia Baetidae nestes dois trechos $(7,3 \%$ e $0,9 \%$ do total capturado, respectivamente).

Os Chironomidae (Diptera) foram capturados em todos os igarapés estudados, porém devido ao fato que a maioria das espécies dos igarapés ser pequenas e fazer parte da mesofauna (Walker, 1987), não foram investigados a fundo neste estudo. No entanto, nos igarapés naturais o número desses foi menor que no Parque Mindú e Zona central onde o gênero Chironomus, considerado bioindicador de ambientes eutrofizados, foi abundante. Presentes também nos trechos urbanizados representantes das familias Culicidae, Ephydridae e Syrphidae.

Moluscos não foram encontrados nos igarapés florestados porém, nas áreas do Parque Mindú e Zona central, cujas águas são enriquecidas por nutrientes somado à presença de capins e macrófitas, que servem de substrato para a deposição dos ovos, a participação percentual destes em relação à composição total foi de $5 \%$ e $20 \%$, respectivamente. Este fato está associado à presença de cálcio nas águas (para confecção da concha) e perifiton nas plantas aquáticas, 
Tabela 3. Dados de Presença (X) e Ausência (-) dos grupos taxonômicos dos macroinvertebrados aquáticos coletados nos locais: $\lg .1$ = igarapé $1, \lg .2$ = igarapé 2, BB= igarapé Barro Branco; $\mathrm{PMM}=$ Parque Municipal do Mindú e $\mathrm{ZC}=$ Zona Central da cidade. Entre parênteses = número total de familias.

\begin{tabular}{|c|c|c|c|c|c|c|}
\hline Ordens & $\begin{array}{l}\text { Familias } \\
(60)\end{array}$ & $\begin{array}{l}\lg .1 \\
(36)\end{array}$ & $\begin{array}{l}\lg .2 \\
(35)\end{array}$ & $\begin{array}{l}\mathrm{Bb} \\
(36)\end{array}$ & $\begin{array}{l}\text { P mm } \\
\text { (26) }\end{array}$ & $\begin{array}{l}\text { Zc } \\
\text { (29) }\end{array}$ \\
\hline Blattodea & Blattidae & $x$ & $x$ & $x$ & - & - \\
\hline \multirow[t]{11}{*}{ Coleoptera } & Brachyp sectridae & $\cdot$ & $\cdot$ & $x$ & - & - \\
\hline & Ceratocanthid ae & $\mathrm{x}$ & $x$ & - & - & $\cdot$ \\
\hline & Curculionidae & - & $x$ & - & - & $x$ \\
\hline & Dytiscidae & $x$ & $x$ & $x$ & $x$ & $x$ \\
\hline & Elmidae & $x$ & $x$ & $x$ & $x$ & $x$ \\
\hline & Gyrinidae & $x$ & - & $\mathrm{x}$ & - & - \\
\hline & Helodidae & $x$ & $x$ & $x$ & - & - \\
\hline & Hydrophilidae & $\mathrm{x}$ & $\mathrm{x}$ & $x$ & $x$ & $x$ \\
\hline & Noteridae & - & $x$ & - & $x$ & $x$ \\
\hline & P tilodactylid ae & - & $x$ & - & - & - \\
\hline & Staphylinidae & $x$ & $x$ & - & - & $\cdot$ \\
\hline \multirow[t]{8}{*}{ Diptera } & Ceratopogonidae & $x$ & $x$ & - & - & , \\
\hline & Chironomidae & $x$ & $x$ & $x$ & $x$ & $x$ \\
\hline & Culicidae & - & - & - & - & $x$ \\
\hline & Ephydridae & - & - & - & $x$ & $x$ \\
\hline & Simuliidae & $\cdot$ & - & $x$ & - & - \\
\hline & Syrphidae & - & - & - & $x$ & $x$ \\
\hline & Tabanidae & $x$ & $x$ & - & . & - \\
\hline & Tipulidae & $x$ & $x$ & $x$ & - & - \\
\hline \multirow[t]{4}{*}{ Ephemeroptera } & Baetidae & $\mathrm{x}$ & $x$ & $x$ & $\mathrm{x}$ & $x$ \\
\hline & Caenidae & $x$ & $x$ & - & $x$ & - \\
\hline & Euthyplociidae & $x$ & $x$ & $x$ & - & - \\
\hline & Lep tophlebidae & $x$ & $\mathrm{x}$ & $x$ & $x$ & $x$ \\
\hline \multirow[t]{6}{*}{ Hemiptera } & Belostomatidae & - & - & - & $x$ & $x$ \\
\hline & Corixidae & $\mathrm{x}$ & $x$ & - & $x$ & $x$ \\
\hline & Gerridae & $x$ & - & $x$ & $x$ & $x$ \\
\hline & Hydrometridae & - & $x$ & $x$ & - & $x$ \\
\hline & Mesoveliidae & - & - & - & - & $x$ \\
\hline & Naucoridae & $x$ & $x$ & $x$ & - & + \\
\hline
\end{tabular}


Tabela 4. Porcentagem de Similaridade $\left(\mathrm{S}=\right.$ Índice de Jaccard), índice de Diversidade $\left(\mathrm{H}^{\prime}=\right.$ Shannon) médio, minimo e máximo e famílias exclusivas dos macroinvertebrados aquáticos (Insecta e Crustacea) dos igarapés 1 e 2 (nascentes do Mindú), trecho no Parque Mindú (trecho urbanizado), Zona central (trecho urbanizado) e Igarapé Barro Branco (igarapé controle) durante o período de 1993 a 1995.

\begin{tabular}{|c|c|c|c|c|c|}
\hline & Igarapé 1 & Igarapé 2 & $\begin{array}{c}\text { Igarapé Barro } \\
\text { Branco }\end{array}$ & Parque Mindú & Zona Central \\
\hline lgarapé 1 & $\begin{array}{c}H^{\prime}=2,27 \\
(1,27-2,58) \\
\text { Nenhuma } \\
\text { familia } \\
\text { exclusiva }\end{array}$ & $S=77,5$ & $S=63,6$ & $S=32$ & $S=22,6$ \\
\hline Igarapé 2 & & $\begin{array}{c}H^{\prime}=2,28 \\
(1,94-2,85) \\
\text { Ptilodactylidae } \\
\text { (Coleoptera) }\end{array}$ & $S=54$ & $S=27$ & $S=25,5$ \\
\hline $\begin{array}{l}\text { lgarapé } \\
\text { Barro } \\
\text { Branco }\end{array}$ & & & $\begin{array}{c}H^{\prime}=2,51 \\
(1,75-2,54) \\
\text { Brachypsectridae } \\
\text { Simulidae, } \\
\text { Corydalidae } \\
\text { Dicteriastidae } \\
\text { Polythoridae }\end{array}$ & $S=29$ & $S=25$ \\
\hline $\begin{array}{l}\text { Parque } \\
\text { Mindú }\end{array}$ & & & & $\begin{array}{c}H^{\prime}=1,76 \\
(1,08-2,24) \\
\text { Trichodactylidae } \\
\text { (Decapoda) }\end{array}$ & $S=66,6$ \\
\hline $\begin{array}{l}\text { Zona } \\
\text { Central }\end{array}$ & & & & & $\begin{array}{c}H^{\prime}=1,54 \\
(1,06-2,18) \\
\text { Culicidae } \\
\text { Mesoveliidae } \\
\text { Pentatomidae } \\
\text { Pleidae } \\
\text { Lestidae }\end{array}$ \\
\hline
\end{tabular}

\section{DISCUSSÃO}

Diversos estudos têm mostrado como os ambientes terrestres e aquáticos no Brasil são alterados diante dos processos de crescimento urbano e populacional (Branco, 1983; Tundisi \& Barbosa, 1995; Silva et al., 1998). As alterações ocorridas no igarapé do Mindú e aqui investigadas apresentaram padrão semelhante encontrado em outras regiões do país (Cardoso, 1989; Beyruth et al., 1993;
Silva, 1995). Tais alterações nas caracteristicas do curso de água urbano - igarapé do Mindú - são uma conseqüência direta do crescimento urbano e adensamento populacional que promoveram, por sua vez, desmatamentos, ocupação desordenada da área, uso inadequado do solo, os quais provocaram intensificação dos processos erosivos e eutrofização das águas resultando em alteração qualitativa das comunidades de invertebrados 
aquáticos e redução da biodiversidade.

Um dos efeitos dos desmatamentos para os pequenos cursos de água é o aumento da temperatura das águas (Steinblums et al., 1984; Barton et al., 1985) visto que sem a cobertura vegetal a incidência da energia radiante torna-se maior. Tal fato foi verificado no igarapé $2\left(1^{\mathrm{a}}\right.$ ordem) nos últimos dois meses de coletas quando iniciou o processo de ocupação da área por três famílias de pessoas (Fig. 2). A temperatura média de suas águas mudou de $25,7{ }^{\circ} \mathrm{C}$ (média para 11 meses) para $28^{\circ} \mathrm{C}$. Já na Zona central da cidade, a ausência de áreas florestadas, maior largura do canal e a estagnação da água na época de cheia conduziram aos maiores valores de temperatura nas águas do Igarapé do Mindú. No entanto, e particularmente nos trechos urbanizados (Parque Mindú e Zona central) que recebem constantemente carga de matéria orgânica, a temperatura pode assumir papel importante na regulação do metabolismo do sistema aquático acelerando os processos de respiração biológica e de decomposição da matéria orgânica repercutindo, por sua vez, no consumo acelerado e conseqüentemente depleção do oxigênio dissolvido limitando a sobrevivência das espécies mais exigentes quanto a esse gás (Stal et al., 1996; Castel et al., 1996)

A cidade de Manaus/AM é drenada por uma densa rede de igarapés e os bairros periféricos não dispõem de serviços adequados de coleta e tratamento de esgotos domésticos. A construção de fossas sépticas e sumidouros, apesar de não contribuir para a deterioração dos igarapés, é prática comum na região porém as casas situadas à beira ou sobre os igarapés (palafitas) despejam os dejetos orgânicos diretamente nos corpos d'água. Isto repercute de maneira negativa não somente nas condições de oxigenação das águas mas nas suas características em geral, principalmente sanitárias (Moura \& Rosa, 1990).

Para os organismos aquáticos, Hynes (1970) e Gore (1994) atestaram que a importância do oxigênio dissolvido nos sistemas de águas correntes está no fato de que durante a fase de desenvolvimento larval, muitas espécies de insetos, principalmente Ephemeroptera e Odonata, movem-se para trechos de alta correnteza e com saturação de oxigênio dissolvido para satisfazer as necessidades fisiológicas. Evidentemente, tais espécies não sobreviveriam nos trechos urbanos eutrofizados.

Além dos desmatamentos na periferia da cidade, os projetos de canalizações, modificações de cursos e aterramentos dos igarapés também aceleram os processos erosivos e de lixiviação do solo (Nava, 1999). Com isto, elevadas quantidades de sedimentos são lançadas nos igarapés agravando o processo principalmente durante o período chuvoso onde o solo, desprotegido da cobertura vegetal, é continuamente lavado e erodido. 
Branco (1983) e Walling \& Webb (1992) mostraram que para os organismos bentônicos uma das conseqüências diretas da entrada contínua de sedimentos é, dependendo do tamanho e composição, o soterramento destes. Também, as partículas podem agir como abrasivos danificando ovos de peixes e dos invertebrados, impossibilitando a colonização de novos ambientes, além de depositar-se na superficie das brânquias dificultando o processo respiratório e de filtração. Estudo feito por Esteves et al. (1990) no lago Batata (Estado do Pará) mostrou que a elevada quantidade de sedimentos argilosos, proveniente do processo de extração de bauxita, soterrou o sedimento originalmente arenoso mudando drasticamente as caracteristicas físicas e químicas deste. Para os organismos bentônicos o aumento na taxa de sedimentação foi significativa levando a eliminação de habitats e de diversas espécies além do aumento na predação e mudanças na qualidade do alimento ingerido pelos filtradores.

Assim, diante das mudanças nos ambientes terrestres (desmatamentos e erosão do solo) e aquáticos (modificações na qualidade das águas) ao longo do igarapé do Mindú, verificou-se uma mudança na composição da fauna de macroinvertebrados aquáticos. E, no caso dos trechos urbanizados e poluídos (Parque Mindú e Zona central), as condições hidrológicas bem como mudanças e homogeneidade dos substratos, entradas constantes de sedimentos e material orgânico (eutrofização) parecem ser os fatores responsáveis pela redução na diversidade da macrofauna aquática. Por outro lado, a eutrofização das águas favoreceu o aparecimento de macrófitas aquáticas, principalmente na zona central da cidade, que assimilam os nutrientes disponiveis, provenientes das descargas de matéria orgânica e que, por sua vez, constituem habitats para uma fauna de invertebrados aquáticos diversa $\mathrm{e}$ também fontes de nutrientes quando decompõem. Fato análogo são os ambientes de várzea onde as águas mais ricas em nutrientes ("águas brancas") constituem ambientes para o desenvolvimento de diversas espécies de macrófitas aquáticas que sustentam uma grande diversidade de peixes (Junk, 1980; Cox-Fernandes \& Petry, 1991).

No entanto, segundo Hynes (1970) e Esteves (1988), na situação de eutrofização da água muitas espécies apresentam redução no número de individuos ou mesmo desaparecimento, sendo substituidas por outras espécies mais adaptadas e que passam a dominar quantitativamente. Para Marchant et al. (1984) e Osborne \& Kovacic (1993), os Trichoptera, Ephemeroptera, Plecoptera e alguns Odonata são considerados intolerantes à poluição orgânica e assim rapidamente eliminados. Neste estudo notou-se que, tanto no Parque Mindú como na Zona central, os Trichoptera e Plecoptera não foram capturados e poucos Ephemeroptera foram 
capturados no Parque Mindú. Quanto aos Odonata, a família Coenagrionidae predominou tanto no Parque como na zona central.

\section{Segundo}

Hynes

Cummins \& Klug

(1970), distribuição dos organismos entre habitats aquáticos disponiveis é geralmente regulada por diversos fatores sendo que um dos mais importantes é a tolerância às condições físicas e químicas da água. A água que flui pelo Parque Mindú e Zona Central apresentou características bem diferentes das águas nas nascentes do Mindú (igarapés 1 e 2) e tais características seguramente inibiram a presença e a distribuição dos organismos aquáticos sensíveis a tais condições. Trichoptera, Plecoptera, Decapoda e grande parte dos Ephemeroptera, que são organismos característicos de águas limpas e com baixa carga de sedimentos em suspensão, não foram capturados nas áreas urbanizadas sendo que nessas áreas dominaram os Diptera (Ephydridae e Syrphidae), Hirudinea e Mollusca (Ancylidae e Pilidae) que são considerados indicadores de águas eutrofizadas. Fato semelhante foi verificado por Beyruth et al. (1993) e Calefi \& Rocha (1993) em ambientes eutrofizados da região metropolitana da cidade de São Paulo/SP onde foi avaliada a qualidade da água e seus bioindicadores sob diferentes graus de influências antrópicas. Os autores observaram a presença de Trichoptera, Ephemeroptera, Odonata, Plecoptera, Hemiptera e Coleoptera nas águas limpas, enquanto que nos ambientes eutrofizados predominaram os Diptera (basicamente Chironomidae e Chaoboridae), Annelida (Hirudinea e Tubificidae) e Mollusca (Physidae).

Também, estudos feitos por Walker (1995) em igarapés de águas claras de terra firme e de águas pretas do igapó do rio Tarumã-mirim (Amazonas) mostraram a composição e diversidade da fauna de invertebrados habitando os bancos de liteira (folhiço) submersa. Grupos encontrados pela autora como Decapoda (camarões do gênero Macrobrachium), Ephemeroptera, Trichoptera e Coleoptera foram também capturados nos igarapés de águas limpas das nascentes (igarapés 1 e 2) do igarapé do Mindú.

Desse modo, verificou-se no estudo a predominância de famílias de acordo com as características do ambiente e conseqüentemente da qualidade da água. Foi o caso das familias Chironomidae (Diptera), Coenagrionidae (Odonata), Belostomatidae (Hemiptera), Hirudinea, Pilidae e Ancylidae (Mollusca) que predominaram nos trechos urbanizados (Parque Mindú e Zona central) e representaram aproximadamente $80 \%$ dos organismos capturados. Já nos igarapés naturais (1,2 e Barro Branco), constatouse o não predomínio de grupos e uma maior biodiversidade. Este fato, dentre outros, pode estar associado a uma ampla variedade de opções tróficas. Em função disso, e como foi mostrado por Kensley \& Walker (1982) e Walker (1994), há poucos grupos especialistas na complexa rede trófica dos igarapés naturais da Amazônia Central sendo as 
cadeias alimentares dos igarapés e pequenos rios da região muito robustas fazendo com que a fauna aquática não seja limitada por alimento e sim por espaço. Para Cummins (1992) os especialistas obrigatórios são facilmente substituídos pelos generalistas quando há distúrbios ambientais, por serem os generalistas mais tolerantes a condições de impacto. No caso dos igarapés que sofrem impactos contínuos, como entrada de sedimentos e carga orgânica (esgotos domésticos), seguramente o padrão de equilibrio é rompido e a rede trófica desestruturada.

As nascentes do Igarapé do Mindú (igarapés 1 e 2), o Parque Mindú e a Zona central da cidade são assim prejudicados pelos desmatamentos e ocupações desordenadas das áreas que refletiram, por sua vez, na qualidade da água do curso d'água urbano.

De acordo com os dados obtidos nesse estudo, diversos fatores estão contribuindo para a degradação do igarapé do Mindú e isto tem afetado drasticamente a comunidade formada pelos macroinvertebrados aquáticos. Também, a eutrofização das àguas, como conseqüência direta do crescimento urbano e populacional, é entendida como um conjunto de fatores de deterioração do referido curso de água que atravessa a cidade de Manaus/AM desaguando no rio Negro.

\section{AGRADECIMENTOS.}

Aos senhores João Batista Santos, José Nunes Palheta, Carlos
Moreira e Lourival Santos pelo apoio nos trabalhos de campo, aos pesquisadores do INPA pelo auxílio na identificação dos organismos e discussão desse estudo. Esse estudo contou com o apoio logístico e financeiro do Instituto Nacional de Pesquisas da Amazônia/INPA e CNPq.

\section{Bibliografia citada}

Barton, D.R.; Taylor, W.D. ; Biette, R.M. 1985. Dimensions of riparian buffer strips required to maintain trout habitat in southern Ontario streams. North American Journal Fisheries Management 5: 364 377

Beyruth, Z.; Calefi, S. ; Rocha, A.A. 1993. Hidrobiologia sanitária e saúde pública em lagos do Parque Ecológico da Zona leste de São Paulo, SP: macroinvertebrados bentônicos. Revista DAE/SABESP, $\mathrm{n}^{0} 172$, 53: $11-14$

Branco, S. M. 1983. Poluição: a morte de nossos rios. CETESB. $155 \mathrm{p}$.

Calefi, S. ; Rocha, S.M. 1993. Variação sazonal da macrofauna bentônica do lago do Parque Ibirapuera (São Paulo) e sua utilização como indicador de poluição. Revista DAE/SABESP, $\mathrm{n}^{0}$ 170, 53: $1-4$

Callisto, M.F.P. \& Esteves, F.A. 1996. Macroinvertebrados bentônicos em dois lagos amazônicos: Lago Batata (um ecossistema impactado por rejeito de bauxita) e Lago Mussurí (Brasil). Acta Limnologica Brasiliensia, 8: 137-47.

Cardoso, M.C.Z. 1989. Participação comunitária em programas de avaliação da qualidade da água. Revista DAE/SABESP, $\mathrm{N}^{0} 157,49: 230-246$

Castel, J.; Caumette, P. ; Herbert, R. 1996. Eutrophication gradients in coastal lagoons as exemplified by the Bassin d'Arcachon and the Étang du Prévost. Hydrobiologia, 329: 9-38

Chauvel, A.; Luca, Y. ; Boullet, R. 1987. On the genesis of the soil mantle of the region 
of Manaus, Central Amazonia, Brasil. Experientia 43: 234-240

Cleto Filho, S.E. N. 1998. Efeitos da ocupação urbana sobre a macrofauna de invertebrados aquáticos de um igarapé da cidade de Manaus/AM - Amazônia Central. Dissertação de Mestrado, Instituto Nacional de Pesquisas da Amazônia/ Fundação Universidade do Amazonas. 74 p.

Cox-Fernandes, C. \& Petry, P. 1991. A importância da várzea no ciclo de vida dos peixes migradores na Amazônia Central. In: Val, A.L., Figliuolo, R. \& Feldberg, E. (Eds.) Bases Cientificas para Estratégias de Preservação e Desenvolvimento da Amazônia: Fatos e Perspectivas. Vol. 1. Instituto Nacional de Pesquisas da Amazônia (INPA), Manaus, 315- 320

Cummins, K.W. 1992. Invertebrates. In: Calow, P. \& Petts, G.E.(Eds.).The Rivers Handbook: Hydrological and Ecological Principles, Volume 1. Blackwell Scientific Publications. $234-250$

Cummins, K.W. \& Klug, M.J. 1979. Feeding ecology of stream invertebrates. Annual Review of Ecology and Systematics, 10: $147-172$

Duncan, W.F.A.; Brusven, M.A.; Bjornn, T.C. 1989. Energy-flow response models for evaluation of altered riparian vegetation in three southeast Alaskan streams. Water Research. 23: $965-974$

Esteves, F.A. 1988. Fundamentos de Limnologia. FINEP/Interciência, Rio de Janeiro, $575 \mathrm{p}$.

Esteves, F.A.; Bozelli, R.L; Roland, F. 1990. Lago Batata: um laboratório de limnologia tropical. Ciência Hoje, 11 (64): 26- 33

Fittkau, E.J. 1977. Kinal and Kinon, habitat and coenosis of the surface drift as seen in Amazonian running waters. Geo.Eco.Trop. 1 (1), 9-20

Fonseca, O.J.M.; Salem, J.I. ; Guarim, V.L. 1982. Poluição e autopurificação do Rio Negro nas cercanias de Manaus. Acta Amazonica, 12 (2): 271- 278

Franken, W. ; Leopoldo, P.R. 1986. Relações entre fluxos de água subterrânea e superficial em bacia hidrográfica caracterizada por cobertura florestal amazônica. Acta Amazonica, 16-17: 253-262

Gore, J.A. 1994. Hydrological Change. In: Calow, P. \& Petts, G.E. (Eds.).The Rivers Handbook: Hydrological and Ecological PrInciples (Blackwell Scientific Publications, Volume 2, $523 \mathrm{p}$.

Hamada, N. 1989. Aspectos bioecológicos de larvas Simulium goeldii (Cerqueira \& Nunes de Mello,1967) com referência a larvas de Simulium rorotaense (Floch \& Abonnenc, 1946) (Diptera: Simuliidae) na Reserva Florestal Ducke, Amazônia Central. Dissertação de Mestrado, Instituto Nacional de Pesquisas da Amazônia/ Fundação Universidade do Amazonas. $106 \mathrm{p}$.

Hynes, H.B.N. 1970. The ecology of running waters. University of Toronto Press, Toronto, Ontario, Canada. 555 p.

IBGE, 1996. Resultados relativos a sexo da população brasileira e situação de unidade domiciliar. Volume 1.

Irmler, U. (1975). Ecological studies of the aquatic soil invertebrates in three inundation forests of Central Amazonia. Amazoniana. Vol.5 : $337-409$

Junk, W.J. 1980. Áreas inundáveis - um desafio para Limnologia. Acta Amazonica, 10 (4): $775-795$

Junqueira, V.M. \& Campos, S.C.M. 1998. Adaptation of the "BMWP" method for water quality evaluation to rio das Velhas watershed (Minas Gerais, Brazil). Acta Limnologica Brasiliensia; 10 (2), $125-135$

Kensley, B. ; Walker, I. 1982. Palaemonid shrimps from the Amazon basin, Brasil (Crustacea: Decapoda: Natantia). Smithsonian Contributions to Zoology 362: $1-28$

Lenat, D.R. 1984. Agriculture and stream water quality: a biological evaluation of erosion control practices. Environment Management $8: 333-344$

Ludwig, J.A.; Reynolds, J.F. 1988. Statistical 
Ecology. John Wiley \& Sons, New York, $339 \mathrm{p}$.

Marchant, R.; Mitchell, P. ; Norris, R. 1984. Distribution of benthic invertebrates along a disturbed section of the La Trobe River, Victoria: An analysis based on numerical classification. Aust. Journal Marine Freswater Res. 35: 355 - 374

Moura, R.C.S.; Rosa, J.F.T. 1990. A questão da saúde na Amazônia. In: Barros, F.A.F. $C$ \& $T$ no processo de desenvolvimento da Amazônia. SCT/CNPq/CEST, Brasília, DF : $153-231$

Nava, D. B. 1999. Mapa da vulnerabilidade aos processos erosivos da porção sudeste da cidade de Manaus, Amazonas. Dissertação de Mestrado. Universidade do Amazonas/Centro de Ciências do Ambiente - $92 \mathrm{p}$.

Oliveira da Silva, R. 1992. Observações sobre a ecologia da comunidade de Odonata (Insecta-Hemimetabola) no igapó e em riachos de terra-firme, na região de Manaus (AM-Brasil). Dissertação de Mestrado. Instituto Nacional de Pesquisas da Amazônia/Fundação Universidade do Amazonas. 85 p.

Osborne, L.L. \& Kovacic, D.A. 1993. Riparian vegetated buffer strips in water quality restoration and stream management. Freshwater Biology, 29 (2): 243-258 p.

Payne, A.I. 1986. The ecology of tropical lakes and rivers. John Wiley \& Sons $\left(1^{\text {a }}\right.$ ed.). New York, 301p.

Radambrasil 1978. Levantamento de recursos naturais. Folha SA-20/Manaus. Rio de Janeiro. Departamento Nacional de Produção Mineral. Volume 18.

Silva, C.P.D. 1995. Community structure of fish in urban and natural streams in the Central Amazon. Amazoniana. 13 (3/4): $221-236$

Silva, A.M.M.; Henry, R.; Carvalho, L.R. \& Santini, J.A.J. 1998. A capacidade de autopurificação de um curso de água: um estudo de caso no Rio Pardo (Botucatu, SP). Acta Limnologica Brasiliensia; 10 (2), $83-99$

Sioli, H, 1975. Tropical river: The Amazon. In:
Whitton, B.A. (Ed.). River Ecology. University of California Press. $461-488$

Sioli, H.1984. The Amazon and its main afluents: hydrography, morphology of the river courses, and river types. In: Sioli, H.; The Amazon: Limnology and landscape ecology of a might tropical river and its basin. Junk, Dordrecht. p. 127-166.

Southwood, T.R.E. 1966. Ecological methods: with particular reference to the study of insect populations. Methuen \& CO. Ltd. $391 \mathrm{p}$.

Stal, L.J.; Behrens, S.B.; Villbrandt, M.; Bergeijk, S. van; Kruyning, F. 1996. The biocheochemistry of two eutrophic marine lagoons and its effect on microphytobenthic communities. Hydrobiologia, 329: $185-198$

Steinblums, I.J.; Froelich, H.A. ; Lyons, J.K. 1984. Designing stable buffer strips for stream protection. Journal of Forestry, 82(1): 49-52

Tundisi, J.G.; Bicudo, C.E.M.; MatsumuraTundisi, T. 1995. Limnology in Brazil. Rio de Janeiro: ABC/SBL; 384 p.

Tundisi, J.G. ; Barbosa, F.A.R. 1995. Conservation of aquatic ecosystems: present status and perspectives. In: Tundisi, J.G.; Bicudo, C.E.M.; Matsumura-Tundisi, T. (Eds.). Limnology in Brazil; 365 - 371

Vásques, C.A.D. 1996. Bionomia de Odonata (Insecta) em dois igarapés da Reserva Florestal Adolfo Ducke (Manaus - AM Brasil). Dissertação de Mestrado. Instituto Nacional de Pesquisas da Amazônia/ Fundação Universidade do Amazonas. 84 p.

Walker, I. (1987). The biology of streams as part of amazonian forest ecology. Experientia, 43, 279-287

Walker, I. 1994. The benthic litter-dwelling macrofauna of the Amazonian forest stream Tarumã-mirim: patterns of colonization and their implications for community stability. Hydrobiologia; 291: 75-92

Walker, I. (1995). Amazonian streams and small rivers. In: Tundisi, J.G.; Bicudo, C.E.M. \& Matsumura-Tundisi, T. (Eds.). 
Limnology in Brazil, 167 - 193

Walker, I. ; Ferreira, M.J.N. 1985. On the population dynamics and ecology of the shrimp species (Crustacea: Decapoda: Natantia) in the Central Amazonian River Tarumã-mirim. Oecologia; 66: 264 - 270

Walling, D.E. \& Webb, B.W. (1992). Water Quality I: Physical Characteristics. In: Calow, P. \& Petts, G.E. (Eds.). The Rivers Handbook: Hydrological and Ecological Principles. Blackwell Scientific Publications, 1: $48-72$ 